\title{
Antimicrobial, free radical scavenging activities and catalytic oxidation of benzyl alcohol by nano-silver synthesized from the leaf extract of Aristolochia indica L.: a promenade towards sustainability
}

\author{
C. Shanmugam ${ }^{1}$ - G. Sivasubramanian ${ }^{2} \cdot$ Bera Parthasarathi $^{3}$ - K. Baskaran ${ }^{4}$. \\ R. Balachander ${ }^{1} \cdot$ V. R. Parameswaran ${ }^{1}$
}

Received: 6 May 2015/ Accepted: 26 June 2015/Published online: 15 July 2015

(c) The Author(s) 2015. This article is published with open access at Springerlink.com

\begin{abstract}
Silver nanoparticles (Ag-NPs) were synthesized from aqueous silver nitrate through a simple route using the leaf extract of Aristolochia indica L. (LAIL) which acted as a reducing as well as capping agent. X-ray diffraction confirmed that the synthesized silver particles have a face centred cubic structure. EDS predicted the presence of elemental silver. The SEM images showed the synthesis of spherically mono-dispersed particles, with nano dimensions accounted by the TEM images. Infra-red spectrum adopted to the different organic functionalities present at the surface of the particles. TGA indicated an overall $11 \%$ weight loss up to $1000{ }^{\circ} \mathrm{C}$, suggesting desorption of biomolecules from the surface. X-ray photoelectron spectroscopy (XPS) analysis revealed the presence of metallic silver nanoparticles. The prepared material was utilized as catalyst in the oxidation of benzyl alcohol with molecular oxygen as the oxidant in methanol, under ambient conditions of temperature and pressure. Also AgNPs showed good to moderate anti-microbial activity employing the Agar disc diffusion method against various strains using Ciprofloxacin and Fluconazole as standard.
\end{abstract}

V. R. Parameswaran

vrpsuschem@gmail.com

1 Department of Chemistry, Annamalai University, Annamalainagar, Chidambaram 608 002, Tamil Nadu, India

2 Department of Chemistry, School of Arts and Sciences, Amrita Vishwa Vidyapeetham, Amritapuri Campus, Amritapuri, Clappana P O, Kollam 690525, Kerala, India

3 Surface Engineering Division, CSIR National Aerospace Laboratories, Bangalore 560017, India

4 Department of Biochemistry and Biotechnology, Faculty of Science, Annamalai University, Annamalainagar, Chidambaram 608002, Tamil Nadu, India
Free radical scavenging activity of the nanoparticles were observed by modified 1,1-diphynyl-2-picrylhydrazyl, DPPH and 2,2-azinobis(3-ethylbenzothiazoline-6-sulfonic acid), ABTS in vitro assays. The work presented here demonstrates the adaptability of the synthesized Ag-NPs in participating as a disinfectant agent, free radical scavenger and an effective oxidation catalyst. The basic premise of attaining sustainability through the green synthesis of smart multifaceted materials has been consciously addressed.

Keywords Aristolochia indica L. · Silver nitrate . Silver nanoparticles - Molecular oxygen ·

Free radical scavenging $\cdot$ Sustainability

\section{Introduction}

Science is the ultimate medium to understand the emerging limits of nature, which spreads its functions ceremoniously in the now ubiquitous nano scale. This manifestation of the nature is replicated by humans in the invention of new materials and technologies which lead to significant knowledge development (Corie Lo 2010) and a sustainable global society. The masquerade facet of Mother Nature can be safely decoded by understanding the disseminated pantomiming prostrated by her. One of this exuberant sampling is the usage of the noble metal silver in its nanoscale. Silver nanoparticles have found applications in fiber optics, single electron transistors, electronic connectors or integral capacitor banks ( $\mathrm{Lu}$ et al. 2006; Li et al. 2005; Chiolerio et al. 2011; Balantrapu and Goia 2009).

Excellent catalytic activity of silver for a number of partial oxidation reactions such as the oxidation of methanol to formaldehyde and ethylene to ethylene oxide is widely known and practiced in industry worldwide. The 
catalytic oxidative power of $\mathrm{Ag}$ is due to its ability to chemisorb oxygen in atomic form. The atomic oxygen could fit into the octahedral holes of $\mathrm{Ag}$ and cause the accumulation of oxygen within the bulk of silver (Nagy and Mest 1999). Pronounced catalytic activity of silver Nanoparticles in the oxidation reaction of styrene was also observed (Xu et al. 2006; Chimentao et al. 2005).

Current research in inorganic nanomaterial's having good antimicrobial properties has opened a new era in pharmaceutical and medical industries. Silver is the metal of choice as they hold the promise to kill microbes effectively. Silver nanoparticles have been recently known to be a promising antimicrobial agent that acts on a broad range of target sites both extra as well as intra-cellularly. Silver nanoparticles shows very strong bactericidal activity against gram positive as well as gram negative bacteria including multi-resistant strains (Shrivastava et al. 2007).

Among the synthetic methods used for the preparation of silver nanoparticles, some toxic chemicals such as $\mathrm{NaBH}_{4}$, citrate, or ascorbate are most commonly used as a reducing agent (Chen et al. 2006; Kuo and Chen 2003). Considering that such reducing agents may be associated with environmental toxicity or biological hazards, the development of green synthesis for silver nanoparticles is desired (Elumalai et al. 2010).

Utilization of plant or plant extract have been suggested as possible ecofriendly alternatives to chemical and physical methods in the preparation of nanoparticles. A thorough survey of the literature reveals that phytosynthesis of nanoparticles is a simple, effective and sustainable approach with practical applicability. Advantages include, eliminating the elaborate process of maintaining cell cultures (Shankar et al. 2004), synthesis in water, possible scale-up, coating of nanoparticles with natural compounds having medicinal properties, thereby reducing cytotoxicity, an otherwise vexed problem in biological applications of nanoparticles. Green synthesis of silver nanoparticles has been reported using extracts of various plants such as Nelumbo nucifera (Santoshkumar et al. 2010), Ocimum sanctum (Singhal et al. 2011), to name a few. Keeping in line with the achieved results, in the literature, it was decided to test the appositeness about the leaves of Aristolochiaceae $\mathrm{L}$, as carrier of reducing phytochemicals. Aristolochia indica L., of Aristolochiaceae is also known as Ishwarballi (Kannada), Indian Birthwort (English), Isharmulv (Hindi), Ishwari (Sanskrit). In Ayurveda the leaves and the roots are used for treatment of fever and insect bites. Aristolochia indica has been also used for other medicinal purposes (Pezzuto et al. 1988). The plant is used to treat cholera, fever, bowel troubles, ulcers, leprosy, poisonous bites (Kanjilal et al. 2009) and also used as emmenagogue, abortifacient, antineoplastic, antiseptic, anti-inflammatory, antibacterial, antioxidant, phospholipase A2 inhibitor (Achari et al. 1983; Chopra et al. 2006; Das et al. 2010) and hyperglycaemic effect (Shanmugam et al. 2014). The major chemical constituents present in the aristolochia extracts are phenanthrene derivatives (Elizabeth and Williamson 2002) like Aristolochia acid (British Pharmaceutical Codex 1911) aristolochic acid-D, aristolochic acid-Dmethyl ether lactum, aristo lactum $\beta$-D glucoside/aristolic acid, aristolic acid, methylester, methyl aristolochate, aristolamide, aristolinic acid, aristolonitrite. Quinones like Aristolindiquinone, lactones like Aristololide, alkaloid like Aristolochine, Terpenes like mono and sesquiterpenes including linalool, $\beta$-caryophyllene, $\alpha$-humulene, ishwarone, caryophyllene oxide, ishwarol, ishwarane and aristolochene and $\alpha$-terpinolene (Christopher wiart 2006).

Antioxidants, retard the formation of toxic oxidation products, maintain nutritional quality, and increase shelf life of foods, by free radical scavenging. Free radicals are created when cells use oxygen to generate energy. These by-products are generally reactive oxygen species (ROS) such as super oxide anion, hydroxyl radical and hydrogen peroxide that result from the cellular redox process. At low or moderate concentrations, ROS exert beneficial effects on cellular responses and immune function but at high levels, free radicals and oxidants generate oxidative stress, a deleterious process that can damage cell structures, including lipids, proteins, and DNA (Pham-Huy et al. 2008). Oxidative stress plays a major part in the development of chronic and degenerative ailments such as cancer, autoimmune disorders, rheumatoid arthritis, cataract, aging, cardiovascular and neurodegenerative diseases (Willcox et al. 2004). Many herbs and spices are the subject of ongoing scientific investigations related to antioxidant properties and health (Kaefer and Milner 2008). Nowadays, there is a growing interest in bio prospecting and the analysis of novel natural antioxidants for use in foods. Namely, some of synthetic antioxidants, such as butylated hydroxyl toluene (BHT) and butylated hydroxyl anisole (BHA), which have been widely used in foods and beverages, showed potential health hazards, because of the formation of possible toxic or carcinogenic components during their degradation (Dastmalchi et al. 2007; Hsouna et al. 2011).

Ag-NPs are reported for diverse biological applications. The study of free radical scavenging activity of these biosynthesized nanoparticles gives an idea about the activity and association of these nanoparticles with biomolecules of living systems. Antioxidants play vital role in the functioning of biological systems by scavenging these fatal free radicals. So far, measurement of antioxidants activity is limited to biological moiety. Few researchers reported antioxidant potential of $\mathrm{Ag}$ nanoparticles. Noble nanoparticles such as Ag-NPs (Banerjee and Narendhira 
Fig. $11 \mathrm{mM}$ aqueous $\mathrm{AgNO}_{3}$ solution with LAIL a before addition the leaf extract and b after addition of leaf extract
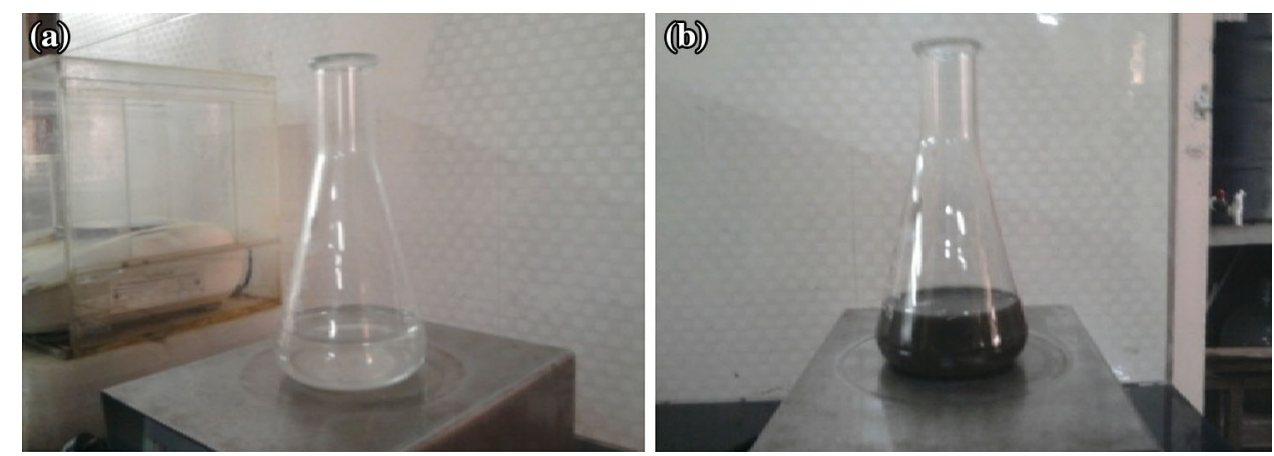

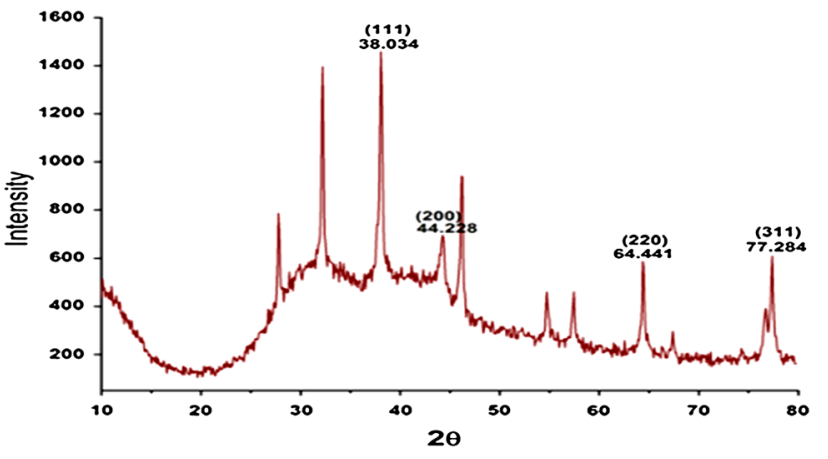

Fig. 2 XRD pattern of synthesized Ag-NPs

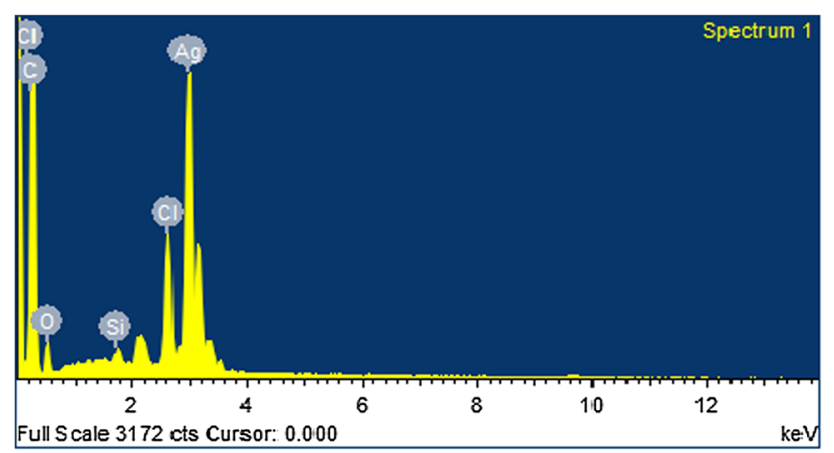

Fig. 3 EDS analysis of synthesized Ag-NPs

kannan 2011; Konwarh et al. 2011) are used as free radical scavenger in in vitro and in vivo systems.

Thus in the present study, it was decided to investigate the formation of silver nanoparticles from leaf extract of $A$. indica L. (LAIL) and to explore the antimicrobial potency of the prepared particles along with the use of these nanoparticles as nano catalysts in the oxidation of benzyl alcohol, with molecular oxygen as the oxidant under ambient conditions of temperature and pressure. In addition in vitro free radical scavenging activity of Ag-NPs are evaluated by two popular free radical scavenging assay 1,1diphenyl-2-picrylhydrazyl (DPPH) and 2,2-azinobis(3ethylbenzothiazoline-6-sulfonicacid) (ABTS). The free radical scavenging activities of Ag-NPs were monitored by $\mathrm{UV}-\mathrm{V}$ is spectroscopy.

\section{Experimental section}

\section{Plant material}

Aerial parts of Aristolochia indica L. were collected in the month of January 2012 from village of Pallividai-612903 in the district of Ariyalur, Tamil Nadu, India. The collected plants were authenticated at Botanical survey of India, Southern Regional Centre, T.N.A.U. Campus, Lawley Road, Coimbatore-641003. Vide letter no: BSI/SRC/5/23/ 2012-13/Tech.

\section{Preparation of leaf extract}

Aristolochia indica L. leaves were collected and washed several times with de-ionized water before it was extracted. $40 \mathrm{~g}$ of this plant leaves were finely cut and stirred with $200 \mathrm{~mL}$ de-ionized water at $80{ }^{\circ} \mathrm{C}$ for $4 \mathrm{~min}$, and filtered to get the extract. The filtrate was used as reducing agent and stabilizer.

\section{Synthesis of Ag nanoparticles using leaf extract of Aristolochia indica L. (LAIL)}

For the synthesis of Ag-NPs, $5 \mathrm{~mL}$ of plant extract were added to $50 \mathrm{~mL}$ of $1 \mathrm{mM}$ aqueous $\mathrm{AgNO}_{3}$ solution in a $250 \mathrm{~mL}$ conical flask. The flask was covered with aluminium foil to prevent light-mediated reduction of silver nitrate. A control setup was also maintained without leaf extract. The Ag-NPs solution thus obtained was purified by repeated centrifugation at $10,000 \mathrm{rpm}$ for $15 \mathrm{~min}$ followed by re-dispersion of the pellet in de-ionized water. Then the Ag-NPs were dried under vacuum.

FT-IR spectrometer Avatar 330 was used for recording the IR spectra of the Ag-NPs using the potassium bromide disc method. 
Fig. 4 SEM images of synthesized Ag-NPs
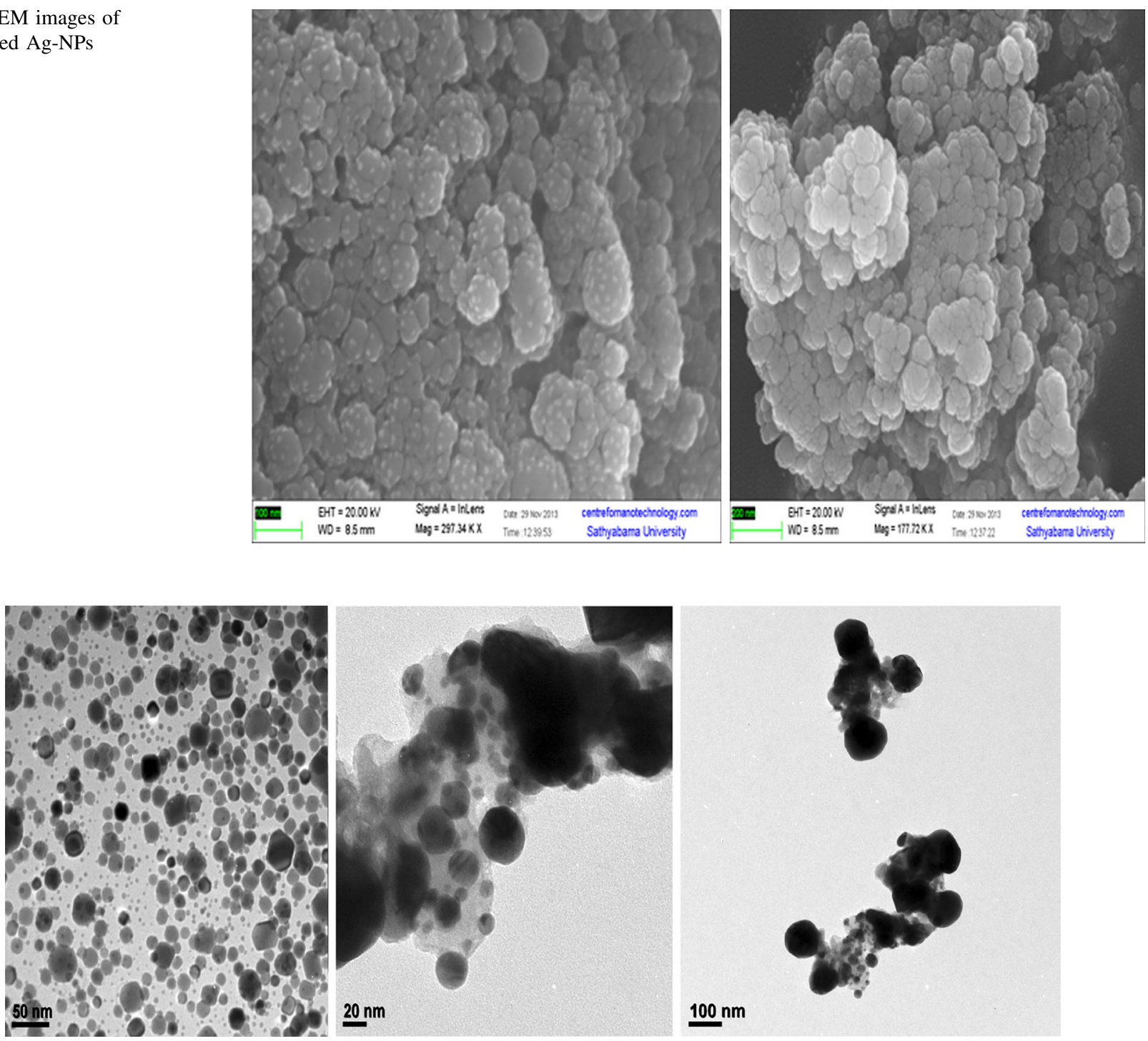

Fig. 5 HRTEM images of synthesized Ag-NPs

X-Ray diffraction was done using Bruker AXSD8 ADVANCE Diffractometer using a $\mathrm{Cu}$ Kalpha radiation of $1.5406 \AA$. DIFFRAC ${ }^{\text {plus }}$ EVA software was used for data evaluation and presentation. The crystal planes obtained were matched with Joint Committee on Powder Diffraction Standards (JCPDS) obtained from The International Centre for Diffraction Data (ICDD), USA.

The surface morphology of the prepared nano silver was characterized using a SUPRA 55 Field Emission-Scanning Electron Microscope from Carl Zeiss AG, Germany.

High resolution transmission electron microscope was employed to characterise the Ag-NPs. The micrographs were obtained in a TECNAI G2 FEI F12 TEM at an accelerating voltage of $200 \mathrm{kV}$. The sample was taken in a vial and dispersed in methanol. A drop if this dispersion was taken in a micro pipette and dropped on carbon coated copper grid (Icon Analytical, mesh 200, type B), kept upon whatman filter paper in a Petri dish. The sample was then dried in a vacuum desiccator for $4 \mathrm{~h}$ and then analysed.

Weight loss and thermal behaviour of the surface capped Ag-NPs was determined by using thermo gravimetric analyser (TGA, Q50).

XPS of Ag nanoparticles were recorded with a Thermo Fisher Scientific, UK spectrometer using non-monochromatic $\mathrm{Al} \mathrm{K} \alpha$ radiation $(1486.6 \mathrm{eV})$ run at $15 \mathrm{kV}$ and $10 \mathrm{~mA}$ as an $\mathrm{X}$-ray source. The binding energies reported here were referenced with $\mathrm{C} 1 \mathrm{~s}$ peak at $284.6 \mathrm{eV}$ with a precision of $\pm 0.1 \mathrm{eV}$. For XPS analysis, powder composite samples were mounted on the sample holder after making into small pellets and kept in the preparation chamber at 
Fig. 6 a FT-IR spectra of LAIL (leaf extract). b FTIR spectra of prepared silver nanoparticles (a)

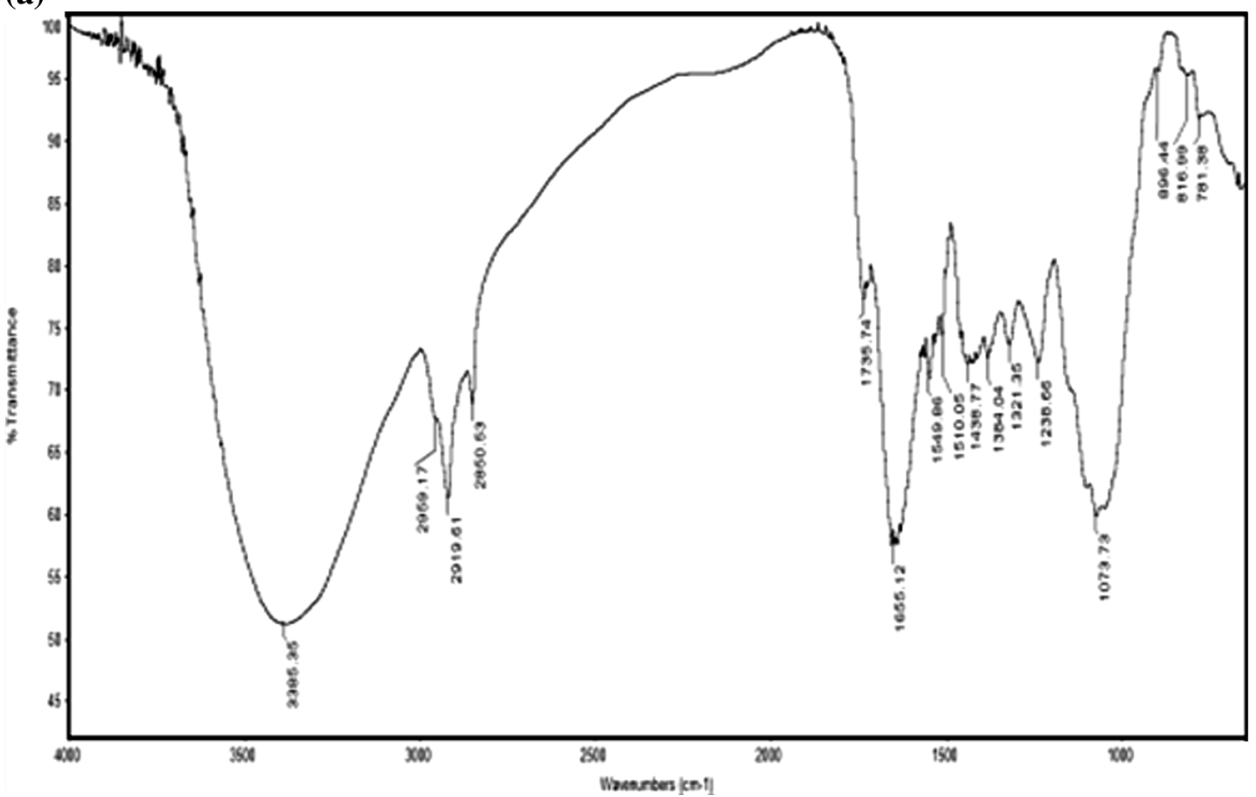

(b)

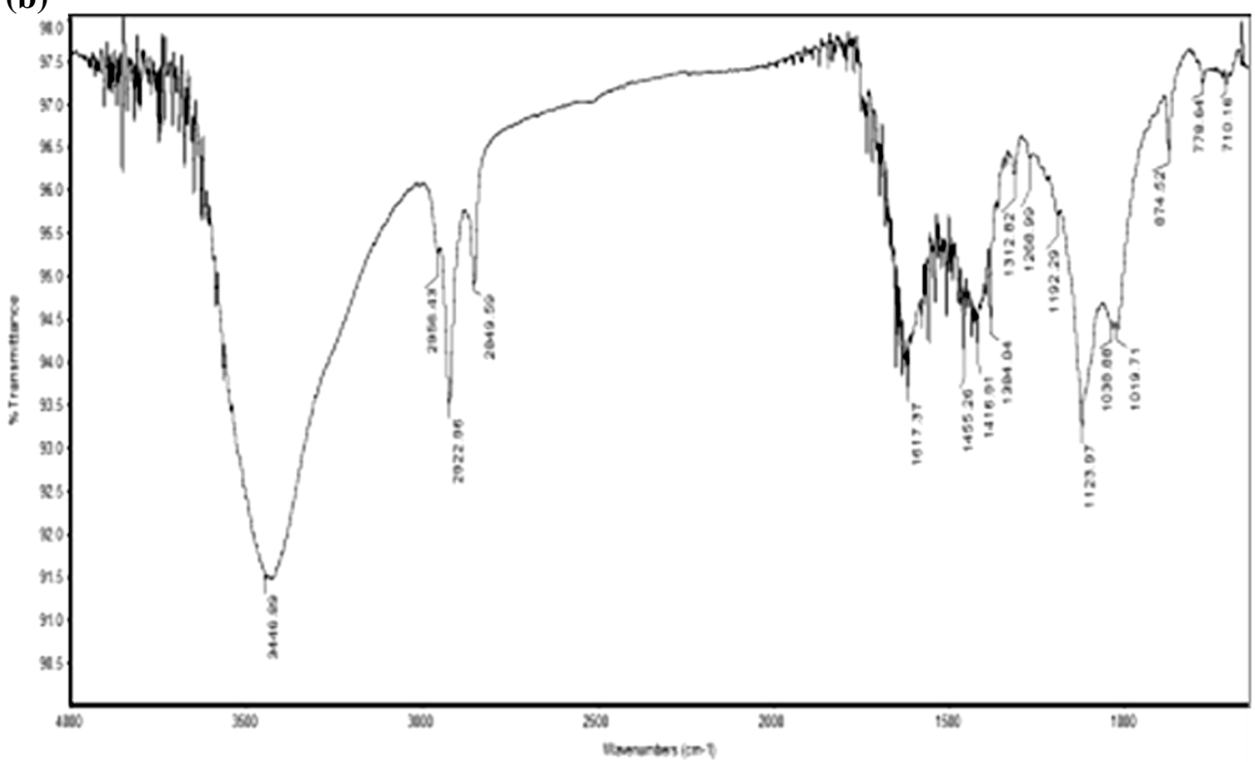

ultrahigh vacuum (UHV) at $10^{-9}$ Torr for $5 \mathrm{~h}$ in order to desorb any volatile species present on the surface. After $5 \mathrm{~h}$, sample was placed into analyzer chamber with UHV at $10^{-9}$ Torr. All the spectra were obtained here in the digital mode with $30 \mathrm{eV}$ pass energy and $0.05 \mathrm{eV}$ step increment.

Gas chromatography mass spectrometry (GC-MS) analysis was carried out using GC model: Varian GC-MSSaturn 2200 Thermo (Varian, the Netherlands) capillary column VF5MS (5\% phenyl-95 \% methyl poly siloxane, $30 \mathrm{~m}$ length, $0.25 \mathrm{~mm}$ internal diameter, $0.25 \mu \mathrm{m}$ film thickness), temperature of column range from 50 to $280{ }^{\circ} \mathrm{C}$ $\left(10{ }^{\circ} \mathrm{C} / \mathrm{min}\right)$ and injector temperature $250{ }^{\circ} \mathrm{C}$.

\section{Chemicals}

Oxygen gas with $99.9 \%$ purity obtained from National Oxygen limited Puducherry was used as the oxidant. Demineralised water (Nice Chemical, Kochi, India) was used throughout the work. The substrate benzyl alcohol and silver nitrate were purchased from Alfa Asear. 1,1-diphenyl-2-picryl hydrazyl (DPPH) was purchased from Sigma 
Fig. 7 TG curve of Ag-NPs synthesized using LAIL

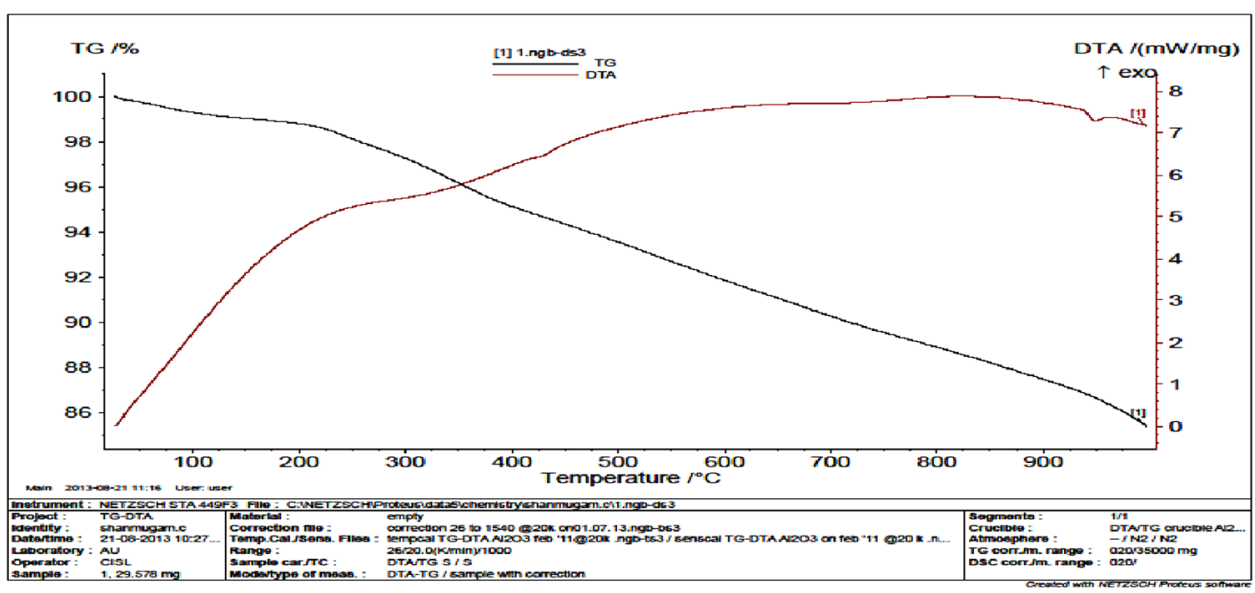

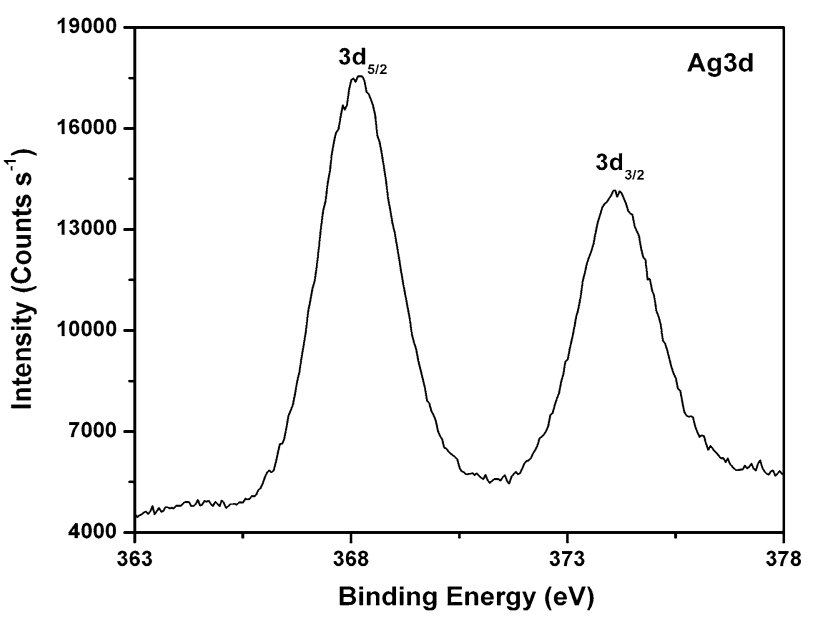

Fig. 8 XPS spectra of Ag-NPs

Chemicals Co.USA. 2,2-azinobis(3ethylbenzothiazoline-6sulfonicacid) (ABTS) were purchased from Merck, Darmstadt, Germany.

\section{Microorganisms}

The target strains used for screening antibacterial and antifungal activity were procured from PCBS, Puducherry. The bacterial strains are Staphylococcus aureus, Bacillus subtilis, Pseudomonas aeruginos, Vibrio cholerae, Escherichia coli, Staphylococcus epidermis, Eubacterium lentum, Enterococcus faecalis. The fungal strains were Candida albicans, Aspergillus flavus, Trichophyton rubrum, Trichophyton mentagrophytes, Trichophyton simii.

\section{Preparation of test pathogens}

The bacteria cultures were grown in Brain Heart Infusion liquid medium at $37^{\circ} \mathrm{C}$. After $12 \mathrm{~h}$ of growth, each microorganism, at a concentration of $1 \times 10^{6}$ cells $/ \mathrm{mL}$

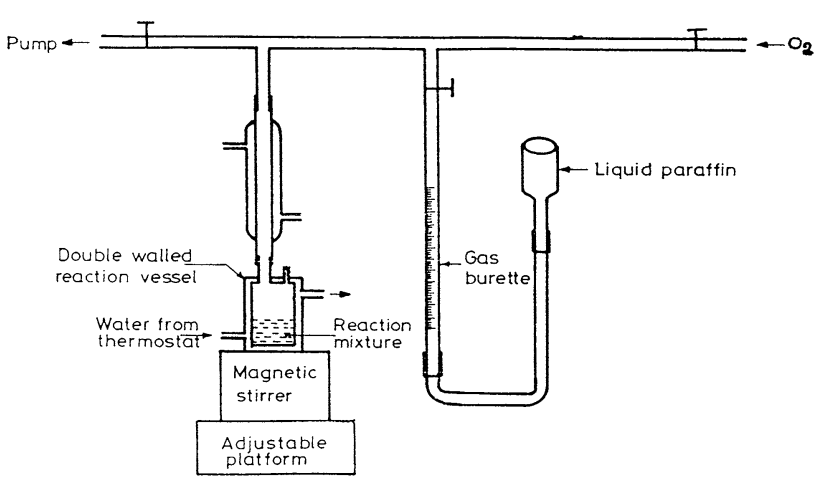

Fig. 9 Static reactor

equivalent to $0.5 \mathrm{McF}$ arland Standard was spread on the surface of Mueller-Hinton agar plates. The dilutions were made in sterile low glucose Nutrient broth.

Test pathogens were spread on the test plates-Mueller Hintion agar (MHA) and $6 \mathrm{~mm}$ diameter well is made in the agar and test material was loaded in $500-50 \mu \mathrm{g} /$ well concentration compared with sterile antibiotic loaded in the well in a concentration of $20 \mu \mathrm{g} /$ well. After $24 \mathrm{~h}$ of incubation the zone of inhibition ( $\mathrm{mm}$ in diameter) was measured and taken as the activity against the test pathogen.

The oxidation reactions were carried out at room temperature in a static reactor using molecular oxygen as the oxidant at one atmospheric pressure. The required amount of the catalyst was taken inside the reaction vessel in the set-up. The system was evacuated and the substrate along with the solvent was introduced into the system by a syringe through a rubber septum. Uniform rate of stirring was maintained. The kinetics of the reaction was followed by the uptake of oxygen using a gas burette as a function of time. Blank experiments were carried out in the absence of catalyst as well as the substrate. In both cases there was no uptake of oxygen. So in both cases reactions did not proceed. 


\section{DPPH radical scavenging activity}

In order to evaluate the in vitro free radical scavenging activity of Ag-NPs, modified DPPH and ABTS assay were used (Serpen et al. 2007). In its radical form, DPPH has an absorption band at $515 \mathrm{~nm}$, which disappears upon reduction by an antioxidant nano particles or a radical species. For the photometric assay, different volumes of the Ag-NPs were taken in different test tubes. The volume was adjusted to $100 \mu \mathrm{L}$ with methanol, $5 \mathrm{~mL}$ of $0.1 \mathrm{mM}$ methanolic solution of $\mathrm{DPPH}^{\bullet}$ was added to these tubes and shaken vigorously. The tubes were allowed to stand for $20 \mathrm{~min}$ at $27^{\circ} \mathrm{C}$. The control was prepared using $5 \mathrm{~mL}$ of $0.1 \mathrm{mM}$ methanolic solution of DPPH. Changes in the absorbance of the samples were monitored at $517 \mathrm{~nm}$. Results were compared with the activity of ascorbic acid. The percentage of DPPH $^{\bullet}$ discolouration of the samples was calculated using the following formula:

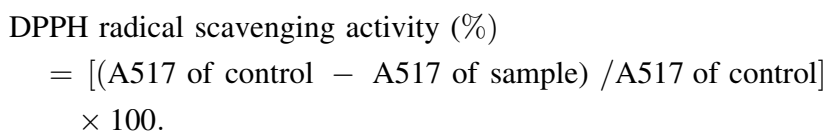

\section{2,2'-Azinobis-(3-Ethylbenzothiazoline-6-Sulfonic Acid) $\left(\mathrm{ABTS}^{+}\right)$Assay}

ABTS $^{\bullet+}$ was produced by reacting $7 \mathrm{mM} \mathrm{ABTS}^{+}$ aqueous solution with $2.4 \mathrm{mM}$ potassium persulfate in the dark for $12-16 \mathrm{~h}$ at room temperature. The radical was stable in this form for more than 2 days when stored in the dark at room temperature. Then, $2 \mathrm{~mL}$ of diluted $\mathrm{ABTS}^{+}$solution was added to the sample varying concentrations of Ag-NPs. The blank contained water in place of Ag-NPs. After $30 \mathrm{~min}$ of incubation at room temperature, the absorbance was recorded at $734 \mathrm{~nm}$ and compared with standard ascorbic acid. Percentage of inhibition was calculated.

$\%$ Scavenging $=\frac{\text { Control OD }- \text { Test OD }}{\text { Control OD }} \times 100$

\section{Results and discussion}

\section{Phyto reduction of silver ions}

A study on phyto-synthesis of Ag-NPs by the aqueous leaf extract of $A$. indica $\mathrm{L}$. was carried out. During the visual observation, silver nitrate with leaf extract showed a colour change from red to brown colour within $24 \mathrm{~h}$ whereas no colour change could be observed in silver nitrate without leaf extract (Fig. 1). This colour arises due to excitation of surface Plasmon vibration in silver Ag-NPs.

\section{XRD analysis}

Analysis of Ag-NPs using X-ray diffraction confirmed the crystalline nature of particles (Fig. 2). A number of Bragg reflections with $2 \theta$ values of $38.034^{\circ}, 44.228^{\circ}, 64.441^{\circ}$ and $77.284^{\circ}$ correspond to the (111), (200), (220) and (311) set of lattice planes, which may be indexed as the band for face centred cubic structure (fcc) of silver. The unassigned peaks could be due to the crystallization of bioorganic phase that occurs on the surface of the nanoparticles. The powder XRD pattern are well agreed with JCPDS vide card numbers $(893722,870720)$.

\section{EDS analysis}

The EDS spectra recorded from the silver nanoparticles are shown in (Fig. 3). The EDS profile shows a strong silver signal along with weak oxygen and carbon peaks, which may have originated from the biomolecules bound to the surface of the silver nanoparticles.

\section{SEM analysis}

The SEM image (Fig. 4) showed high density Ag-NPs synthesized by the. The SEM micrographs of nanoparticles obtained in the filtrate showed that Ag-NPs are spherical in shape and were poly dispersed without conglomeration in solution.

\section{TEM analysis}

Transmission electron microscopy was used to investigate the microstructure and crystallinity of the silver nanoparticles synthesized using LAIL. It is clear from high resolution TEM image (Fig. 5) that the as prepared $\mathrm{Ag}$ nanoparticles possess spherical shape.

\section{FTIR analysis}

FT-IR analysis was carried out to identify the possible biomolecular interaction responsible for formation and stabilization of silver nanoparticles. The result of FT-IR analysis is presented in Fig. 6a, b. The (Fig. 6a) shows the FT-IR spectrum of LAIL that did not contain $\mathrm{AgNO}_{3}$, whereas (Fig. 6b) shows spectrum of extract containing $\mathrm{AgNO}_{3}$.

FTIR spectra (Fig. 6a) showed transmission peaks at $1549.86,1438.77,1384.04,1321.35,1238.66,1073.73$, $896.44,816.99$ and $781.38 \mathrm{~cm}^{-1}$. The broad signal at $3385.35 \mathrm{~cm}^{-1}$ is indicative of $(\mathrm{OH})$ hydroxyl and $\mathrm{NH}$ stretching vibrations. Aliphatic and aromatic $\mathrm{C}-\mathrm{H}$ stretching vibrations are observed at 2959.17, 2919.61 and $2850.53 \mathrm{~cm}^{-1}$ respectively. High intense bands at 1735.74 , 
$1655.12 \mathrm{~cm}^{-1}$ could be assigned to COO (carboxylic) and $\mathrm{C}-\mathrm{N}$ stretching frequency. The peaks at 1549.86 and $1510.05 \mathrm{~cm}^{-1}$ are due to $\mathrm{CO}, \mathrm{C}-\mathrm{O}$ groups of aliphatic amines. The peaks around $1070 \mathrm{~cm}^{-1}$ are attributed to $v_{\mathrm{C}-\mathrm{O}-\mathrm{C}}$ mode. The sharp peaks at $890 \mathrm{~cm}^{-1}$ is due to $v_{\mathrm{N}-\mathrm{O}}$ stretching vibration of leaf extract.

FT-IR study indicates that the carboxyl $(-\mathrm{C}=\mathrm{O})$, and amine $(\mathrm{N}-\mathrm{H})$ groups in LAIL are mainly involved in reduction of $\mathrm{Ag}^{+}$ions to $\mathrm{Ag}^{0}$. The FT-IR spectroscopic study also confirmed that the organic functional groups present in LAIL acts as a reducing agent and stabilizer for the silver nanoparticles and prevents agglomeration.

FTIR spectrum (Fig. 6b) was examined to identify the possible biomolecules responsible for capping and efficient stabilization of the Ag-NPs synthesized by plant leaf extract. The peaks observed for Ag-NPs formed through reduction by LAIL, are elaborated as follows (all values in $\mathrm{cm}^{-1}$ ): The broad peak observed at $3446 \mathrm{~cm}^{-1}$ is due to hydroxyl group and aliphatic $\mathrm{CH}$ stretching accounts around 2922-2956 $\mathrm{cm}^{-1}$. The peak at $1617 \mathrm{~cm}^{-1}$ stands for $\mathrm{C}-\mathrm{N}$ stretching frequency and nitro group stretching frequency observed at $1455 \mathrm{~cm}^{-1}$ because of $1416 \mathrm{~cm}^{-1}$ belongs to aromatic $=\mathrm{CH}$ bending stretching frequency. The frequencies at 1038 and $1019 \mathrm{~cm}^{-1}$ are due to $\mathrm{C}-\mathrm{O}-\mathrm{C}$ ether linkage. These peaks suggest the presence of various organic functional groups adsorbed on the surface of AgNPs and corroborates well with the biomolecules, extracted from $A$. indica L., documented in the literature (Elizabeth and Williamson 2002; British pharmaceutical codex 1911; Christopher wiart 2006).

These changes in the infrared spectra suggested that organic functional groups might act as a reductant. As we know that the LAIL contains a lot of reductive organic functional groups; they may have participated in the reduction reaction as well.

\section{Thermal studies}

The thermal stability of Ag-NPs was studied using TGA which showed that the NPs synthesized by plant extract began to degrade at around $300{ }^{\circ} \mathrm{C}$ (Fig. 7). Also, there is a steady weight loss until $1000{ }^{\circ} \mathrm{C}$. The total weight loss up to $1000{ }^{\circ} \mathrm{C}$ for $\mathrm{Ag}-\mathrm{NPs}$ synthesized using LAIL was $11.11 \%$. The observed behaviour is most likely as a consequence of the surface desorption of bio-organic compounds present in nanoparticle powder. Thus, plant leaf extract-stabilized Ag-NPs are expected to be made up of molecules responsible for the reduction of metal ion and stabilizing particles in the solution. This result suggests that natural products present in LAIL are responsible for the reduction of $\mathrm{Ag}^{+}$to $\mathrm{Ag}^{0}$ (nanoparticles). The extract not only act as the reducing agent but also as the capping material.
Table 1 Synthesized Ag-NPs (catalyst). Rate of oxidation for the substrates [Catalyst] $\times 10^{3} \mathrm{M}=0.40$

\begin{tabular}{ll}
\hline Substrate $(0.2 \mathrm{M})$ & Rate $\times 10^{3}\left(\mathrm{M} \mathrm{min}^{-1}\right)$ \\
Benzyl alcohol & 0.82 \\
\hline
\end{tabular}

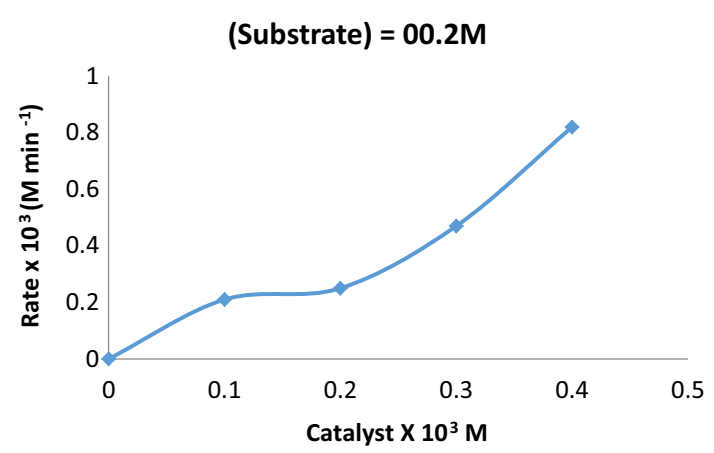

Fig. 10 Dependence of rate on amount of the catalyst for Ag-NPs

\section{XPS analysis}

Ag3d core level spectra of Ag nanoparticles are displayed in (Fig. 8) $\mathrm{Ag} 3 \mathrm{~d}_{5 / 2,3 / 2}$ core level peaks at 368.2, $374.1 \mathrm{eV}$ with $5.9 \mathrm{eV}$ spin-orbit separation correspond to Ag metal (Moulder et al. 1979).

\section{Oxidation}

The prepared nano silver can catalyse organic reactions. In order to test this assumption, the Nanosilver was implicated as a catalyst for the oxidation of benzyl alcohol to benzaldehyde. The test proved that nano silver is active for oxidation of benzyl alcohol at ambient conditions of temperature and pressure using molecular oxygen as the oxidant. The as prepared Ag-NPs contain biomolecules adhered to the surface as evidenced from IR. These did not show any appreciable conversion for the oxidation reaction. Subsequently the Ag-NPs were subjected to heating above $900{ }^{\circ} \mathrm{C}$ in a muffle furnace to remove any biomolecules. The temperature for this treatment was found from TGA.

The oxidation reactions were carried out at room temperature in static reactor (Fig. 9) using molecular oxygen as the oxidant at one atmospheric pressure. The reactor was charged with the desired amount of catalyst and the system was evacuated. The substrate diluted with the solvent was injected through a rubber septum. Uniform rate of stirring was maintained. The kinetics of the reaction was followed by the uptake of oxygen using a gas burette as a function of time. Blank experiments were carried out in the absence of catalyst as well as the substrate. In both cases there was no oxygen uptake. So in both cases reactions did not proceed. 
Fig. 11 a Gas chromatograph and mass spectra-before oxidation. b Gas chromatograph and mass spectra-after oxidation (a)

MS Data Review Active Chromatogram and Spectrum Plots - 9/3/2013 10:52 AM

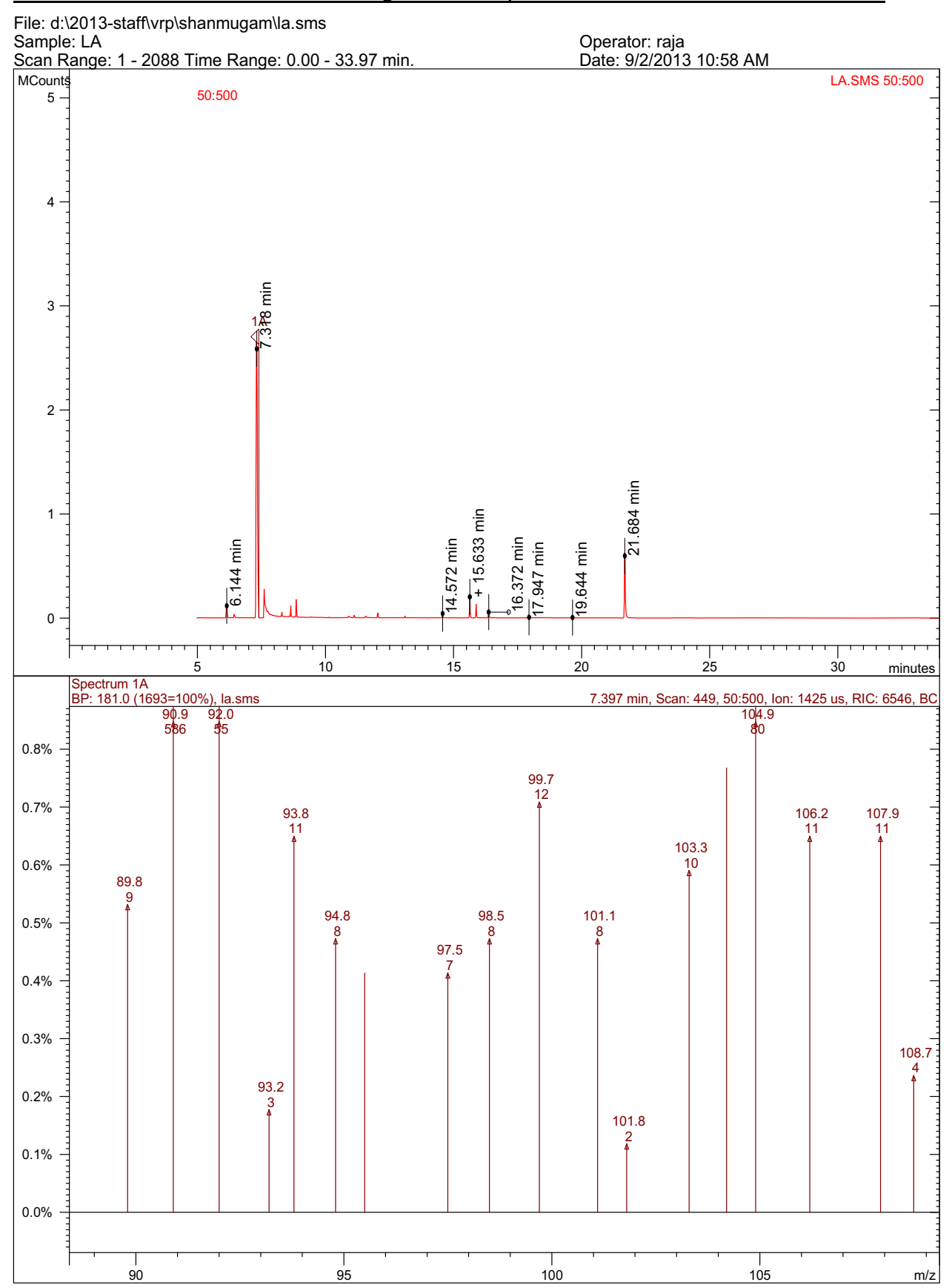

Methanol, a protic non coordinating solvent was used through the experiments as the solvent. The results of the oxidation are summarized in the (Table 1). The rates of reaction increase linearly up on increasing the concentration of both the catalyst and the substrate (Fig. 10). Thus rate of oxidation is proportional to [catalyst] [substrate]. The catalyst was found to be efficient for $4-5$ runs. The turn over number, calculated from the initial rates is 2788 $(\mathrm{g} \text { atom of } \mathrm{Ag})^{-1} \mathrm{~h}^{-1}$.

\section{Product analysis}

The formation of benzaldehyde was detected using GCMS technique. The chromatogram and the corresponding mass spectra were recorded for the substrate as well as the product of oxidations. The results are shown in (Fig. 11a, b).

The chromatogram for the reaction mixture before oxidation shows peak of benzyl alcohol. The sample recorded 
Fig. 11 continued

(b)

MS Data Review All Plots - 9/3/2013 10:25 AM

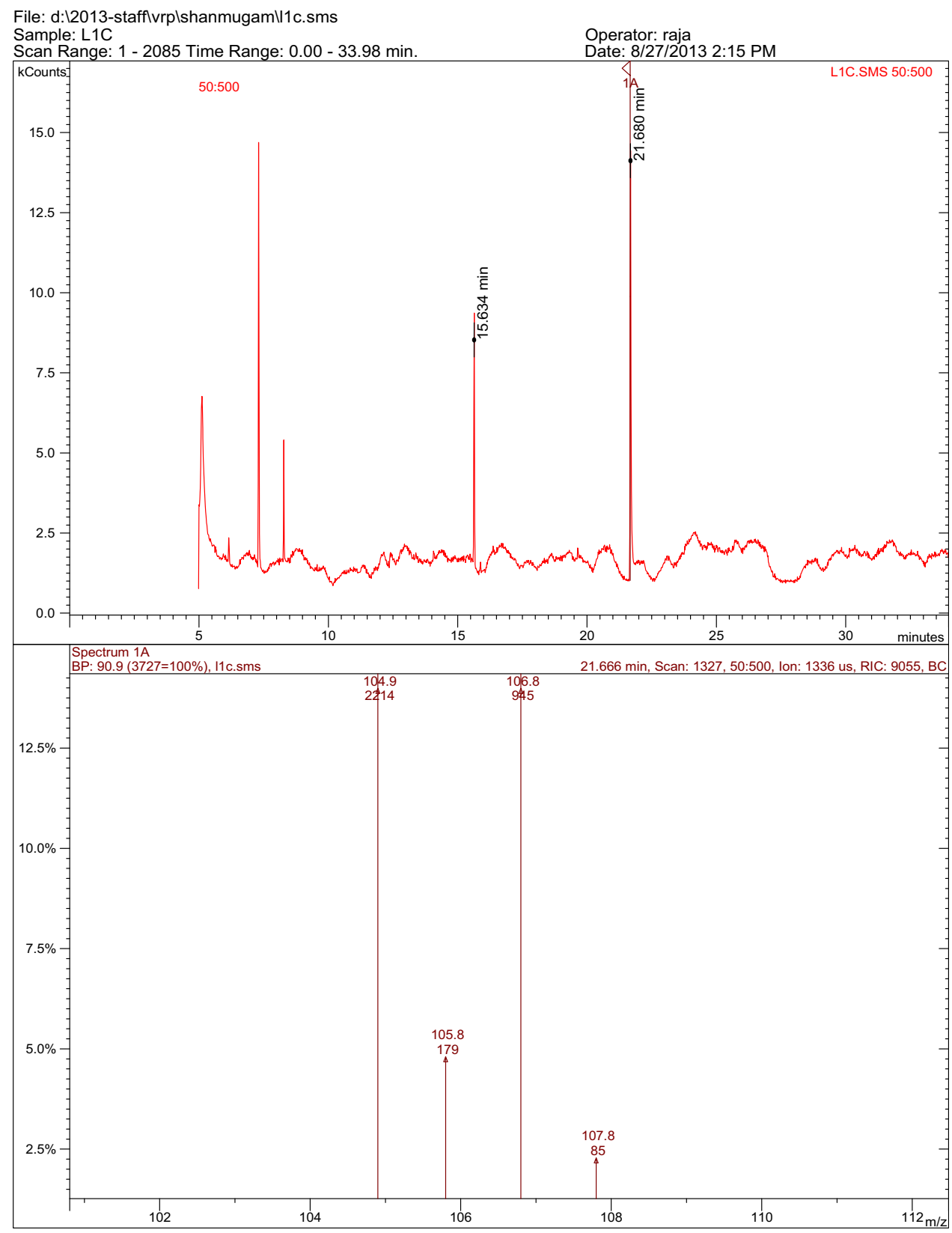

after the reaction showed peaks, one for the product benzaldehyde and other for unreacted benzyl alcohol. The mass fragmentation peaks are given in (Tables 2, 3).

\section{Antimicrobial activity}

In vitro antimicrobial activity of $\mathrm{Ag}-\mathrm{NPs}$ - the antibacterial and antifungal activities of Ag-NPs against eight bacteria and five fungal are presented in (Table 4, 5). The silver nanoparticles were assayed against the test organisms by disc diffusion assay (Bauer et al. 1966). The ciprofloxacin control produced zone of inhibition was between 22.0 and $40.0 \mathrm{~mm}$ and fluconazole control produced zone of inhibition were between 12.0 and $18.0 \mathrm{~mm}$.

The prepared Ag-NPs was found active against five bacterial strains viz, S. aureus, E. faecalis, E. coli, S. epidermis and $B$. subtilis. The zone of inhibition values are given in Table 4 and the images of the agar plates containing Ag-NPs impregnated disks and the zone of inhibition for various bacterial and fungal pathogens used in the current study are given in (Fig. 12a, b) respectively. Staphylococcus aureus, a gram positive bacteria is the most susceptible of all the 
Table 2 Mass fragmentation for the reaction mixture

\begin{tabular}{ll}
\hline Mass fragments & $m / z$ \\
\hline M & 108 \\
M-1 & 107 \\
M-17 & 91 (base peak) \\
\hline
\end{tabular}

$M$ molecular mass

Table 3 Mass fragmentation for the oxidation product

\begin{tabular}{ll}
\hline Mass fragments & $\mathrm{m} / \mathrm{z}$ \\
\hline $\mathrm{M}$ & 106 \\
$\mathrm{M}+1$ & 107 (base peak) \\
\hline
\end{tabular}

$M$ molecular mass

Table 4 Antibacterial activity of synthesized Ag-NPs

\begin{tabular}{lll}
\hline Bacteria & \multicolumn{2}{l}{ Zone of inhibition in mm of diameter } \\
\cline { 2 - 3 } & $\begin{array}{l}\text { Ag-NPs } \\
(500 \mu \mathrm{g} / \mathrm{disc})\end{array}$ & $\begin{array}{l}\text { Positive control } \\
\text { Ciprofloxacin } \\
(5 \mu \mathrm{g} / \mathrm{disc})\end{array}$ \\
\hline Staphylococcus aureus & 11 & 35 \\
Enterococcus faecalis & 9 & 28 \\
Escherichia coli & 9 & 30 \\
Staphylococcus epidermis & 9 & 35 \\
Bacillus subtilis & 7 & 23 \\
Eubacterium lentum & Not active & 25 \\
Pseudomonas aeruginos & Not active & 22 \\
Vibrio cholera & Not active & 40 \\
\hline
\end{tabular}

Table 5 Antifungal activity of synthesized Ag-NPs

\begin{tabular}{lll}
\hline Fungi & \multicolumn{2}{l}{ Zone of inhibition in mm of diameter } \\
\cline { 2 - 3 } & $\begin{array}{l}\mathrm{Ag}-\mathrm{NPs} \\
(500 \mu \mathrm{g} / \mathrm{disc})\end{array}$ & $\begin{array}{l}\text { Positive control } \\
\text { Fluconazole }(5 \mu \mathrm{g} / \mathrm{disc})\end{array}$ \\
\hline Candida albicans & 13 & 17 \\
Trichophyton simii & 12 & 15 \\
$\begin{array}{l}\text { Aspergillus flavus } \\
\begin{array}{l}\text { Trichophyton } \\
\text { rubrum }\end{array}\end{array}$ & 12 & 17 \\
$\begin{array}{l}\text { Trichophyton } \\
\text { mentagrophytes }\end{array}$ & 12 & 18 \\
\hline
\end{tabular}

bacterial strains under study. Literature cites various mechanisms like attachment of nanoparticles to the surface of the cell-thereby penetrating the cell membrane to release silver ions, causing cell death. Also silver ions could produce free radicals, leading to the rapture of the cell membrane and untimely death of the cell. They could also react with the phosphorus or sulphur moieties of DNA, inhibiting DNA replication (Chen et al. 2014). We predict that the observed tendency of Ag-NPs could be because of the action along any one of these reported pathways. Likewise the prepared nanoparticle has been found potent against five fungal strains (C. albicans, T. simii, A. flavus, T. rubrum, T. mentagrophytes). Interestingly Ag-NPs are more active against fungal strains than the bacterial strains and have their zone of inhibition values very proximal to the standard values. One of the drawbacks of using silver nanoparticles is the accompanied toxicity. This problem can be overcome by using surface coatings. In the current work, biomolecules present in the leaf extract can act as the surface coating material.

\section{Free radical scavenging activity}

During biosynthesis of Ag-NPs, numerous antioxidants of LAIL act synergistically as confirmed by FTIR analysis. These antioxidants compounds might get adsorbed onto the active surface of Ag-NPs. Surface reaction phenomenon of these biosynthesized Ag-NPs (due to adsorbed antioxidant moiety onto the surface) and high surface area to volume ratio of Ag-NPs generate a tendency to interact and scavenge this free radical.

\section{DPPH scavenging activity}

The antioxidant activities were determined by using 1,1diphenyl-2-picryhydrazyl (DPPH) as a free radical. The DPPH scavenging activity of Ag-NPs was determined by its absorbance at $570 \mathrm{~nm}$, which is due to the presence of antioxidants. The percentage of DPPH radical scavenging activity of Ag-NPs were expressed in (Fig. 13). This shows the maximum DPPH scavenging activity of Ag-NPs were $81.19 \%$ at $100 \mu \mathrm{g} / \mathrm{mL}$ whereas ascorbic acid (standard) was found to be at $86.24 \%$ at $100 \mu \mathrm{g} / \mathrm{mL}$. DPPH radical is considered to be a model of lipophilic radical. In this mode, scavenging activity is attributed to hydrogen donating ability of antioxidants (Philips et al. 2010). Although Ag-NPs possess good DPPH scavenging activity, it was evident that the $\mathrm{Ag}$-NPs could serve as free radical inhibitors or scavengers.

\section{ABTS $^{+}$Scavenging activity}

The percentage of $\mathrm{ABTS}^{+}$radical scavenging activity of Ag-NPs were expressed in (Fig. 14). Ag-NPs displayed a maximum $\mathrm{ABTS}^{+}$scavenging activity of $64.01 \%$ at $100 \mu \mathrm{g} / \mathrm{mL}$ whereas for ascorbic acid (standard) it was found to be $70.25 \%$ at $100 \mu \mathrm{g} / \mathrm{mL}$. ABTS assay is an excellent tool for determining the antioxidant activity of hydrogen ion donating antioxidants and of chain-breaking antioxidants (Leong and Shui 2002). 

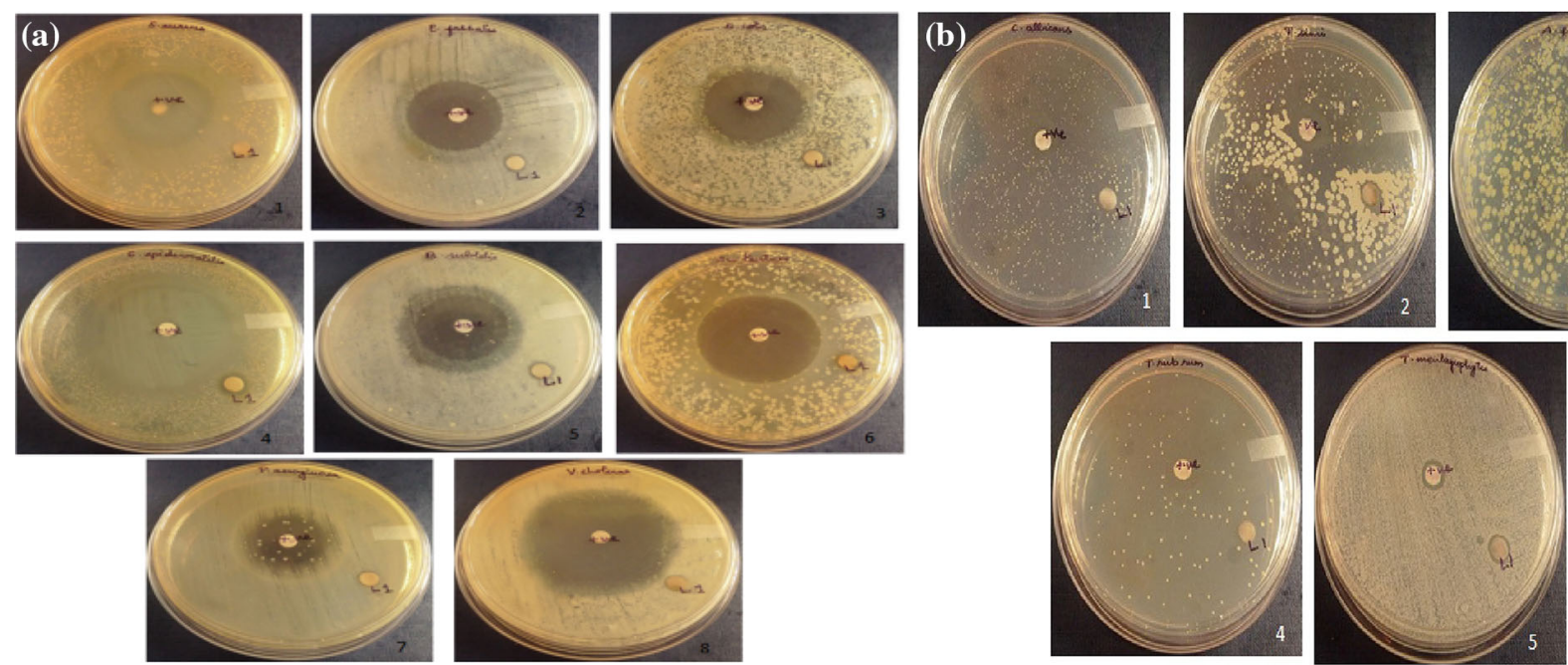

Fig. 12 a Representative images of agar plates containing synthesized Ag-NPs impregnated disks—bacterial strains. b Representative images of agar plates containing synthesized Ag-NPs impregnated disks-fungal strains

Ag-NPs on DPPH assay

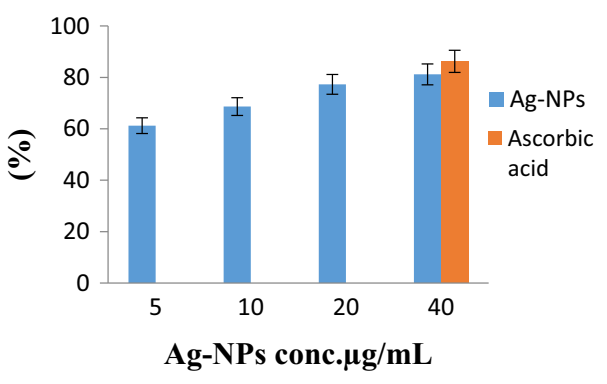

Fig. 13 Effect of synthesized Ag-NPs on DPPH assay

\section{Conclusion}

We carried out a phyto mediated synthesis of nano-sized $\mathrm{Ag}$ particles using leaf extract of Aristolochia indica L. This work demonstrates the use of a natural, renewable and low cost phyto reducing agent to produce metal nanostructure in aqueous solution at room temperature thus avoid the input of hazardous and toxic solvents. The prepared material has shown promise as catalyst for the oxidation of benzyl alcohol using molecular oxygen under ambient conditions of temperature and pressure. Mild reaction conditions, avoidance of hazardous oxidants and solvent, good catalytic recycling efficiency and appreciable turnover number make the process attractive alternative. The prepared nano silver also show good antimicrobial activities. Biosynthesized Ag-NPs shows considerable potential in in vitro trials for DPPH and ABTS free radical scavenging activity. The process and the results established in this paper thrust a new beginning about the use of natural

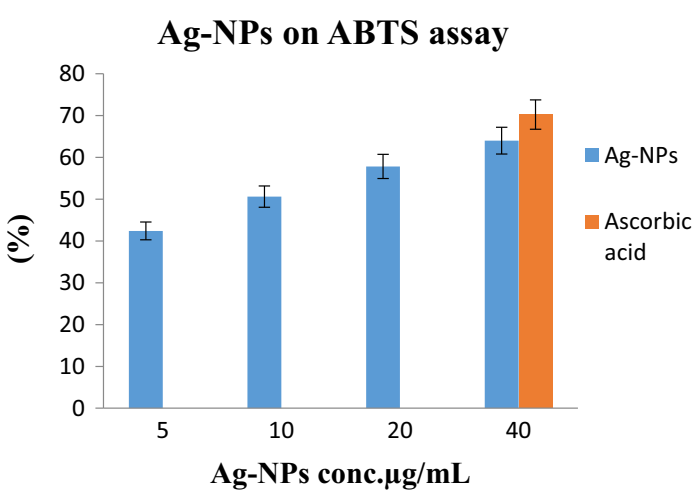

Fig. 14 Effect of synthesized Ag-NPs on ABTS assay

resources, conceptual thinking and simple logistics to attain the important goal of sustainability.

Open Access This article is distributed under the terms of the Creative Commons Attribution 4.0 International License (http:// creativecommons.org/licenses/by/4.0/), which permits unrestricted use, distribution, and reproduction in any medium, provided you give appropriate credit to the original author(s) and the source, provide a link to the Creative Commons license, and indicate if changes were made.

\section{References}

Achari B, Bandopadhyay S, Saha CR, Pakrashi SC (1983) A phenanthroid lactone, steroid and lignans from Aristolochiaindica. Heterocycles 20:771-774

Balantrapu K, Goia DV (2009) Silver nanoparticles for printable electronics and biological applications. J Matt Res 24:2828-2836

Banerjee J, Narendhira kannan RT (2011) Biosynthesis of silver nano particles from Syzygium cumini (L.) seed extract and evaluation 
of their in vitro antioxidant activities. Dig J Nano Mater Bio Struct 6:961-968

Bauer AW, Kirby WMM, Sherris JC, Truck M (1966) Antibiotic susceptibility testing by a standardized single disk method. Am J Clin Pathol 45(2):493

Chen M, Wang LY, Han JT, Zhang JY, Li ZY, Qian DJ (2006) Preparation and study of poly acryamide-stabilized silver nanoparticles through a one-pot process. J Phys Chem B 110:11224

Chen CW, Hsu CY, Lai SM, Syu WJ, Wang PY, Lai PS (2014) Metal nano bullets for multidrug resistant bacteria and biofilms. Adv Drug Deliv Rev

Chimentao RJ, Kirm I, Medina F, Rodríguez X, Cesteros Y, Salagre P (2005) Sensitivity of styrene oxidation reaction to the catalyst structure of silver nanoparticles. Appl Surf Sci 252:793-800

Chiolerio A, Maccioni G, Martino P, Cotto M, Pandolfi P, Rivolo P (2011) Inkjet printing and low power laser annealing of silver nanoparticle traces for the realization of low resistivity lines for flexible electronics. Microelectron Eng 88:2481-2483

Chopra RN, Nagar SL, Chopra IC (2006) Glossary of medicinal plants, 7th edn. National Institute of Science communication and communication and Information resources, p 24

Christopher wiart (2006) Ethnopharmacology of medicinal plants, Asia and the Pacific. Humana press, pp 4-6

Corie Lo K (2010) Small wonders. Nature 467:18-21

Das R, Kausik A, Pal TK (2010) Anti-inflammatory activity study of antidote Aristolochia indica to the venom of Heteropneustes fossils in rats. J Chem Pharm Res 2:554-562

Dastmalchi K, Dorman HJD, Kosar M, Hiltunen R (2007) Chemical composition and in vitro antioxidant evaluation of a watersoluble Moldavian balm (Dracocephalum moldavica L.) extract. Food Sci Technol 40:239-248

Elizabeth M, Williamson (2002) Major herbs of India-Major chemical constituents of phenanthrene derivatives Aristolochic acid from Aristolochia indica. Major Herbs of Ayurveda, p 41

Elumalai EK, Prasad TNVKV, Kambala V, Nagajyothi PC, David E (2010) Green synthesis of silver nanoparticle using Euphorbia hirta $\mathrm{L}$ and their antifungal activities. Arch Appl Sci Res 2:76-81

Hsouna AB, Trigui M, Culioli G, Blache Y, Jaoua S (2011) Antioxidant constituents from Lawsonia inermis leaves: isolation, structure elucidation and anti-oxidative capacity. Food Chem 125:193-200

Kaefer CM, Milner JA (2008) The role of herbs and spices in cancer prevention. J Nutr Biochem 19:347-361

Kanjilal PB, Kotoky R, Couladis M (2009) Chemical composition of the stem oil of Aristolochia indica L. J Essent Oil Resid 21:1-2

Konwarh R, Gogoia B, Philip R, Laskar MA, Karaka N (2011) Biomimetic preparation of polymer-supported free radical scavenging, cytocompatible and antimicrobial green silver nanoparticles using aqueous extract of Citrus sinensis peel. Colloid Surf B 84:338-345

Kuo PL, Chen WF (2003) Formation of silver nanoparticles under structured amino groups in pseudo-dendritic poly (allylamine) derivatives. J Phys Chem B 107:11267

Leong LP, Shui G (2002) An investigation of antioxidant capacity of fruits in Singapore markets. Food Chem 76:69-75
Li Y, Wu Y, Ong Facile BS (2005) Synthesis of silver nanoparticles useful for fabrication of high conductivity elements for printed electronics. J Am Chem Soc 127:3226-3227

$\mathrm{Lu}$ J, Moon KS, Xu J, Wong CP (2006) Synthesis and dielectric properties of novel high-K polymer composites containing in situ formed silver nanoparticles for embedded capacitor applications. J Mater Chem 16:1543-1548

Moulder JF, Stickle WF, Sobol PE, Bombem KD (1979) In: J. Chastain (ed), Handbook of X-ray photoelectron spectroscopy. Perkin-Elmer Corporation, Eden Prairie, Minnesota, p 184

Nagy A, Mest G (1999) High temperature partial oxidation reactions over silver catalysts. Appl Catal A 188(1-2):337-353

Pezzuto JM, Swanson SM, Mar W, Che CT, Cordell GA, Fong HH (1988) Evolution of the mutagenic acid cytostatic potential of Aristolochic acid (3,4-methylenedioxy-8-methoxy-10-nitrophenanthrene-1-caroxylic acid) and several of its derivatives. Mutat Res 206:447-454

Pham-Huy LA, He H, Pham-Huyc C (2008) Free radicals, antioxidants in disease and health. Int J Biomed Sci 4(2):89-96

Philips A, Philips S, Arul V, Padmakeerthiga B, Renju V, Santha S (2010) Free radical scavenging activity of leaf extracts of Indigo feraaspalathoides-an in vitro analysis. J Pharm Sci Res $2: 322-328$

Santoshkumar T, Rahuman AA, Rajakumar G, Marimuthu S, Bagavan A, Jayaseelan C, Zahir AA, Elango G, Kamaraj C (2010) Synthesis of silver nanoparticles using Nelumbo nucifera leaf extract and its larvicidal activity against malaria and filariasis vectors. Parasitol Res 108:693-702

Serpen A, Capuana E, Fogliano V, Gokmen V (2007) New procedure to measure the antioxidant activity of insoluble food components. J Agric Food Chem 55:7676-7681

Shankar SS, Rai A, Ahmad A, Sastry M (2004) Rapid synthesis of $\mathrm{Au}, \mathrm{Ag}$, and bimetallic $\mathrm{Au}$ core-Ag shell nanoparticles using Neem (Azadirachta indica) leaf broth. J Colloid Interface Sci 275:496-502

Shanmugam C, Baskaran K, Sivasubramanian G, Balachender R, Pugalendi KV, Parameswaran VR (2014) Aristolochia indica L. methanol root extract suppresses hyperglycemic effect in STZinduced diabetic rats model. Asian $\mathrm{J}$ Biochem Pharm Res 4:2231-2560

Shrivastava S, Bera T, Roy A, Singh G, Ramachandra Rao P, Dash D (2007) Characterization of enhanced antibacterial effects of novel silver nanoparticles. Nanotechnology 18:9

Singhal G, Bhavesh R, Kasariya K, Sharma AR, Singh RP (2011) Biosynthesis of silver nanoparticles using Ocimum sanctum (Tulsi) leaf extract and screening its antimicrobial activity. J Nanopart Res 13:2981-2988

The British Pharmaceutical codex (1911) Published by council of pharmaceutical society of Great Britan

Willcox JK, Ash SL, Catignani GL (2004) Antioxidants and prevention of chronic disease. Crit Rev Food Sci Nutr 44:275-295

Xu R, Wang D, Zhang J, Li Y (2006) Shape-dependent catalytic activity of silver for the oxidation of styrene. Chem Asian J 1:888-893 